\title{
Knowledge Management in Public Transportation: Experiences in Brazilian Bus Companies
}

Hélcio Raymundo, Oduvaldo Vendrametto, and João Gilberto Mendes dos Reis

Paulista University, Postgraduate Studies Program in Production Engineering

Dr. Bacelar 1212, 04026-002 São Paulo, Brazil

\{helcioru, oduvaldov\}@uol.com.br,

betomendesreis@msn.com.br

\begin{abstract}
The Brazilian public transportation system is composed of small and medium size companies. These companies may not be prepared to thrive in a competitive environment because, generally, these firms are managed like a family business. Thus, Knowledge Management (KM) can be defined as an efficient and simple way to solve day-to-day problems and drive the quality of services. Knowledge Management System (KMS) is a business process developed to encompass a basic investigative process, which consists of a synthetic diagnosis of the general conditions and the establishment of programs aimed at the generation of improvements based on the reduction and or elimination of wastefulness. This paper presents KM methodology (KM and KMS) applied in three case studies in Brazilian bus companies. The results indicate that application of this methodology allows companies to reach a competitive advantage. This paper is a result of consulting services in these companies.
\end{abstract}

Keywords: Bus companies, KM, KMS, Public transportation.

\section{Introduction}

Brazil is the largest country in Latin America (8.5 million sq. km), with a population of almost 200 million inhabitants. In 2013, Brazil was the 7th economy in the world [1], considering the GNP in purchasing power parity (US 2.5 trillion dollars), behind the US, China, India, Japan, Germany and Russia.

The Brazilian public transportation system encompasses rail services (tram / metro systems and trains) and bus services. In the eight major Brazilian cities, including São Paulo and Rio de Janeiro, there are tram/metro systems, while trains operate, in general, in metropolitan areas. All the rail services are operated by large public companies that carried 2.60 billion passengers in 2012 [2]. On the other hand, bus services are extremely popular and the preferred method of transport in Brazil. Over 19.23 billion passengers are carried per year by around 3,870 operators with a fleet of 183.1 thousand buses. The bus services can be divided into three main categories, as shown in Table 1.

B. Grabot et al. (Eds.): APMS 2014, Part II, IFIP AICT 439, pp. 603610 2014.

(C) IFIP International Federation for Information Processing 2014 
Table 1. The Brazilian Bus Transportation Systems in Figures of 2011

\begin{tabular}{cccc}
\hline Services & $\begin{array}{c}\text { Passengers } \\
\text { Carried } \\
\text { (billion) }\end{array}$ & $\begin{array}{c}\text { Companies } \\
\text { (units) }\end{array}$ & $\begin{array}{c}\text { Fleet of } \\
\text { Buses } \\
\text { (thousands) }\end{array}$ \\
\hline International and Interstate (a) & 0.13 & 260 & 18.7 \\
Intercity (b) & 1.40 & 1,810 & 57.0 \\
City and Metropolitan (c) & 17.70 & 1,800 & 107.4 \\
Total & 19.23 & 3,870 & 183.1 \\
\hline
\end{tabular}

Source: Adapt [3], 4] [5], and [6]

The bus services are operated by small and medium size companies, normally family companies. Family businesses are a predominant type of organization in various industries in Brazil, and contribute significantly in economic and social terms, employing over $60 \%$ of the available workforce [7]. There are specific traits that are seen as characteristics of Brazilian family companies, such as the trend toward informality, centralism, the non-acceptance of methodical management, tends to paternalism in labor relations and "the aversion to risk and lack of managerial maturity" 7]. As a consequence, family businesses in general and private operators of bus services in particular, face many difficulties in management, failing to adapt to new market demands. This occurs because the business owners tend to centralize decisions and be disinclined to radical changes, especially those that represent a break with traditional culture and work habits.

In this context, considering the several aspects involved and what really matters to solve the day-to-day problems in bus companies, knowledge management (KM) and knowledge management systems (KMS) were tested as useful tools to understand, interpret, analyze and provide feasible solutions. The literature of this field is vast, which, however, does not avoid the establishing of practical applications that can benefit family businesses from the theoretical foundations.

Thus, a strong conceptual basis was found from a comprehensive historical view, in terms of: "knowledge is a broad and abstract notion that has defined the epistemological debate in western philosophy since the classical Greek era" and "in the past few years, however, there has been a raging interest in treating knowledge as a significant organizational resource" [8].

Following this conceptual basis, the state of art of KM and KMS and an organized guide of tangible applications 9]. Additionally, useful elements are shown, teaching how to cope with changes in the business in the everchanging environment and how to apply KM and KMS through technological means [10].

It was also possible to learn the way to apply KMS in different levels of communication technology, even without them, in an eye-to-eye relationship with the "owners" of the knowledge in a company [11. In turn, by means of a literature review, consolidates and updates the majority of concepts until now found in the above references and allows a broader understanding of the concept of KM [12. 
Finally, the practical application of KM is connected with the theoretical basis and [13] while Hislop analyzing it used in business until recently, produces a critical analysis of the importance and benefits of KM [14], serving as one of the guides for the methodology developed and applied in this paper.

Under these conditions, it can be said that the purpose of this paper is to describe a typical application of the KM methodology, according to the concept that KM and KMS can be represented by the strategies and processes designed to identify, capture, structure, value, leverage, and share an organization's intellectual assets to enhance its performance and competitiveness [14]. This methodology is based on two critical activities: (1) capture and documentation of individual explicit and tacit knowledge; and (2) its dissemination within the organization [12].

With the purpose of testing the methodology proposed, three case studies were conducted in Brazilian bus companies. These enterprises operate in the Brazilian public transportation system and this research is a result of a consulting service provided to them.

\section{Methodology}

Three bus companies were studied to show KM methodology application in operations of Public Transportation. These companies were coded A, B and C. The criterion used to select the enterprises was to choose those to which $\mathrm{KM}$ methodology was applied, regardless of type, size and location.

Considering that this research was a result of a consulting service, the five stages of the investigative process were made, following KM techniques: (1) Characterization of the Problems, (2) Diagnosis, (3) Suggested Solutions, (4) Proposed Actions and (5) Analysis of Results.

Characterization of the Problems: this step is sought for troubleshooting, related to problems generally demonstrated through the manifestation of its more harmful effects. Thus arises what here can be called "Fact Generator" or "Main Problem".

Diagnosis: is to find evidence by identifying the origins of problems through their symptomatic manifestations. Similar to a process of determining by examining the nature and circumstances of a problematic condition, Diagnosis also could be defined as: (1) a decision reached from such an examination; (2) an analysis of the cause of a problem or situation; or (3) an answer to a problem situation.

Suggested Solutions: are actionable solutions, applications to be discussed. Sometimes, even adequately proven in the Diagnosis, there are difficulties in evaluation and consolidation of the solutions and their relationship with the Suggested Solutions, due to the incorrect interpretation of the way of combatting the problems. In this step, whenever necessary, the consultant must reiterate the tactical and/or strategic character of the Suggested Solutions.

Proposed Actions: the Suggested Solutions are implemented and monitored in their effective implementation and measurement of qualitative and 
quantitative indicators of interest. The retrospective evaluation of indicators of interest can then perform analysis "before/after".

Analysis of Results: the results are demonstrated by the evolution of the indicators of interest, confirmation of problems resolution and benefits achieved.

\section{Case Studies}

The Table 2 shows general information about the companies studied.

Table 2. General Characterization of Selected Bus Companies

\begin{tabular}{cccccc}
\hline $\begin{array}{c}\text { Bus } \\
\text { Company }\end{array}$ & Size & $\begin{array}{c}\text { Number } \\
\text { of Garage }\end{array}$ & $\begin{array}{c}\text { Main } \\
\text { Service }\end{array}$ & $\begin{array}{c}\text { Market } \\
\text { Share(\%) }\end{array}$ & $\begin{array}{c}\text { City or Region } \\
(\mathbf{1 , 0 0 0} \text { inhabitants) }\end{array}$ \\
\hline (A) & 300 & 1 & Urban & 10 & $>20,000$ \\
(B) & 30 & 1 & Urban & 100 & 75 \\
(C) & 25 & 1 & Urban & 10 & 250 \\
\hline
\end{tabular}

The selected companies are operating in different cities and regions of Brazil. Company A still has its headquarters in São Paulo, whose metropolitan area is the largest in Brazil. Companies $\mathrm{B}$ and $\mathrm{C}$ are functioning in small and midsize cities located in the countryside of Minas Gerais.

\subsection{Case 1}

The "Main Problem" of company A was the loss of $10 \%$ of the passengers in a few of its lines by the action of illegal transportation. Company A was well organized in a consolidated structure and presented a reasonable level of professionalization. Thus, the Diagnosis phase indicated that in accordance with the results of an opinion poll of passengers and drivers, this pointed to a mismatch between the service provided and the desired service. The Suggested Solution was to change the service in order to provoke direct competition with illegal transportation.

The Government Agency placed itself publicly against the illegal transportation, while maintaining a contradictory policy to "legalize" these services. In doing so, the Government Agency could not approve the Suggested Solution. This would have consisted of, among other actions, the implementation in the lines most effected by the competition of express services with air conditioning minibuses, only for seated passengers at peak hours, in a higher level of offer than the usual. The minibuses would initially be hired for subsequent operation in "leasing" or permanent acquisition.

A pilot test of a week was performed (Test 1) only with the normal company fleet of common buses, as if they were minibuses, resulting in a recovery of about $5 \%$ of passengers. The Government Agency, however, did not approve 
Test 1. Then another solution was developed (Test 2), consisting of: (1) Maintenance of the official timesheet, rigorously fulfilling the programming; (2) Use of solely brand new vehicles, equipped with "suggestion boxes". (3) Ensuring of a sufficient fleet of vehicles on standby in the garage, in order to fix problems related to congestions, vehicle breakdowns or overcrowding; and (4) Designation of the best drivers and conductors properly uniformed and instructed to treat passengers as preferred customers.

The recovery of demand in the Test 2 was less than the Test 1 , reaching a maximum of $2 \%$. The comparison of the tests, however, was revelatory. The Test 1 provoked a small addition of costs, of $1 \%$ to $2 \%$. The Test 2 , on the other hand, showed an increase of more than $10 \%$ of costs.

Under these conditions, another opinion poll was performed and revealed, considering all the suggestions and criticism from passengers, that it was clear that the improvement of quality was welcome, but most of them (more than $50 \%$ ) wanted in the morning peak hours more speed, agility and comfort. The passengers' opinions also showed that drivers and conductors were attentive and well-intentioned, but seemed not to understand the needs of passengers.

As a result of these tests, the company opened two fronts. An internal one, with extra costs limited to $2 \%$, applying customer service training for drivers and conductors and changing operational procedures to provide increased reliability and regularity to their services. The second front, external, branched out in two actions: (1) addressed to the Government Agency, assisting them in monitoring the services; (2) had an institutional character, and involved the participation of a representative of the Board of Directors at meetings and forums held by the NTU (Brazilian National Association of Urban Transport Companies) and ANTP (National Association of Public Transport) related to discussion and dealing with solutions to illegal transportation.

As a result, the company $\mathrm{A}$, even having not fully recovered the lost demand, has absorbed part of the illegal transportation impacts by reducing costs and is better prepared to face the problem of competition with them. The most important aspect however is that the enterprise had learned a new way of coping with their problems from their own experience and their internal resources.

\subsection{Case 2}

The "Fact Generator" of the company B was related to the management. The Bus company was a small one, with a low degree of professionalization and a fleet of buses aged between 4 and 5 years. They implemented a computerized system of control, at the request of the minor owner. The senior partner, however, could not "feel" any type of economy generated by the new system, in spite of considering it "revolutionary".

The Diagnosis phase revealed that the computerized system, in fact, did not reduce costs, but accelerated additions of new controls of little or no use. Besides, it was possible to verify that profitability was satisfactory, but had decreased in recent years, due to the adjustment of fares lower than the growth of the costs 
and due to the growth in the wastefulness level in the company. The latter event was related to their (informal) police, represented by the following beliefs:

- "Old buses serve only to "drink" oil and squander tires and parts" (the words of the head of maintenance); and

- "Drivers and conductors are a breed that there's no way to control" (the words of the head of operations).

Based on the simple principle that there is no administration without controls and controls must generate actions, firstly it was established what should be controlled. Under this principle, the Suggested Solution was to transform the new computerized system into a supporting decision-making system and to implement a program to reduce the wastefulness.

Low-cost programs were also deployed, such as 5S, a supplier management program and some specific training actions for mechanics. In the operational area, the drivers were updated through training in safe driving.

In a second phase, the partners defined which indicators would be monitored and the goals to be pursued. This process was discussed with the head of maintenance, head of operations and staff representatives of each area of the company. In three months, adverse trends were reversed with a reduction of costs between $10 \%$ and $20 \%$. Overcoming this phase, the company B implemented a program of fleet renewal and today is experiencing an increase in profitability levels.

\subsection{Case 3}

The company $\mathrm{C}$ operated lines of low profitability. It was also experiencing a lack of resources to pay off short-term commitments and a high level of debt. This was due to the implementation of financial reorganization, which was poorly conducted, and was still in progress. As a result, there were difficulties for the renewal of the fleet (buses with an average age of 7 years).

The Diagnosis phase showed $75 \%$ of revenue committed to the operational activities and a vicious circle represented by:

- The aging of the fleet increased the operation and maintenance costs and decreased the cost of depreciation;

- The reduction of depreciation cost was never compensated by the increases in costs of operation and maintenance; and

- The loss of income reflected in the day-by-day of the bus company, represented by high production losses.

As the situation became critical, the company renewed part of the bus fleet using finance in unfavorable terms, paying high interest rates, which made financial costs grow, increasing the pressure of rising costs and preventing future purchases of new. The Suggested Solution recommended was to "break" this vicious circle through:

- Implementation of a recovery program to reduce the debts supported by a complete austerity in the use of resources of the company; 
- Monitoring and control of each line in order to improve performance measured by the indicators of (a) passengers carried per distance travelled by the fleet and (b) passengers per bus per day;

- Management actions to improve the schedules of the lines;

- Applying training at all levels of the workforce;

- Management of suppliers in order to obtain price reductions

- Management to reduce indirect costs (insurance, taxes, fees etc.); and

- Implementation of a fleet management system.

These measures should be implemented and evaluated. Every $10 \%$ reduction in expenditure meant the possibility of buying a new bus. If the average age was reduced by 3 or 4 years an immediate reduction of $15 \%$ of the costs would be obtained.

The enterprise implemented the measures suggested and today has a commitment of $60 \%$ of revenue with the operation and the average age of the fleet has dropped to 4.5 years. It was not planned, but there was an increase of $5 \%$ in demand for better quality of services and reduction of production losses. A quality program was initiated recently and has revealed opportunities for additional reduction of costs.

\section{Conclusion and Outlook}

The cases showed the applied methodology of KM. Even in the case of partial implementation of the Suggested Solutions, the application of KM always generates some kind of benefit to the companies, putting them in more favorable positions in terms of corporate training, profitability, competitiveness and reduction of wastefulness.

It's possible to come to the conclusion that KM methodology is a tool which helps to utilize some available resources of bus companies in a smart and efficient way to achieve higher business goals in a productive fashion. It was also shown that it's possible, with low cost or nearly no cost, to reach the development of new opportunities, creating value, obtaining competitive advantages and improving performance to attain the objectives of bus companies and their emerging needs, as indicated in references [9], [10, 11], 12], [13], and [15].

Under these conditions, it is recommended that further studies should be done and more cases should be developed to confirm the results showed here and allow the consolidation of a KM methodology that can be applied to the majority of bus companies in the world.

\section{References}

1. Central Intelligence Agency: The world fact book, https://www.cia.gov/library/publications/ the-world-factbook/geos/br.html

2. National Association of Public Transport of Rails, www.anptrilhos.org.br 
3. National Agency of Land Transport: Annual Report, 5th edn., vol. 9. ANTT, Brasilia (2009)

4. Brazilian Association of Companies for Road Passenger Transport, http://www.abrati.org.br/page/11728

5. National Association of Public Transport: Relatório comparativo 2003-2011 (2012)

6. Brazilian National Association of Urban Transport Companies: Dados do transporte público por ônibus, http://www.ntu.org.br/novo/AreasInternas. aspx?idArea=7

7. Almeida, E., Melo, M.C.D.L.: Implantação do processo de sucessão em uma empresa familiar de transportes: Desafios e contradições, Resende, pp. 1-17 (2012), http://www.aedb.br/seget/artigos12/511630.pdf

8. Alavi, M., Leidner, D.E.: Knowledge Management and Knowledge Management Systems: Conceptual Foundations and Research Issues. SEAD Working Paper Series, Fontainebleau (1999)

9. Gamble, P.R., Blackwell, J.: Knowledge Management: A State of the Art Guide. Kogan Page Publishers (2001)

10. Botha, D.A., Kourie, D.G., Snyman, R.: Coping With Continuous Change in the Business Environment: Knowledge Management and Knowledge Management Technology. Chandos Publishing (Oxford), Limited (January 2008)

11. Maier, R.: Knowledge Management Systems: Information and Communication Technologies for Knowledge Management. Springer (June 2007)

12. Anand, A., Singh, M.: Understanding knowledge management: a literature review. International Journal of Engineering Science and Technology 3(2), 926-939 (2011)

13. Dalkir, K.: Knowledge Management in Theory and Practice. Elsevier Science (June 2005)

14. Business Dicionary, http://www.businessdictionary.com/definition/knowledge-management.html

15. Hislop, D.: Knowledge Management in Organizations: A Critical Introduction. Oxford University Press (January 2013) 